\title{
Assessing the Environmental Awareness among the Farmers of Namakkal District about the Eco-Friendly Poultry Waste Management Techniques
}

\author{
S. P. Sasi* and K. Suganya \\ Department of Environmental Sciences, Tamil Nadu Agricultural University, \\ Coimbatore, India \\ *Corresponding author
}

A B S T R A C T

\begin{tabular}{l} 
K e y w o r d s \\
Poultry waste, \\
$\begin{array}{l}\text { Environmental } \\
\text { impact, Awareness, } \\
\text { Manure }\end{array}$ \\
\hline Article Info \\
$\begin{array}{l}\text { Accepted: } \\
15 \text { October } 2020 \\
\text { Available Online: } \\
10 \text { November } 2020\end{array}$ \\
\hline
\end{tabular}

Survey of poultry waste management in Namakkal district was carried out in four villages namely, Mohanur, Valayapatty, Ladduvaddi, Parali. The main purpose of the study is to assess the awareness among the people of the selected villages of Namakkal district about the poultry waste management and its disposal viz., manure, electricity, production etc., through questionnaire survey. Awareness of the electricity production from poultry droppings in selected villages was $21 \%$. Most of them are using the poultry waste as manure to the crops and remaining excess waste was sent to Kerala and they used waste as manure in their Coconut and Arecanut field. Based on the questionnaire survey, it has been found that only $25 \%$ waste was used in villages as manure. $75 \%$ poultry waste was sent to Kerala. From the study, it was clearly noticed that nearly $50 \%$ of people are unaware of risks of improper disposal of waste before the awareness given.

\section{Introduction}

Poultry sector in India is valued at about Rs. 80,000 crore (2015-16) broadly divided into two sub-sectors - one with a highly organized commercial sector with about $80 \%$ of the total market share (say, Rs. 64,000 crore) and the other being unorganized with about $20 \%$ of the total market share of Rs. 16,000 Crore. The unorganized sector also referred to as backyard poultry which plays a key role in supplementary income generation and family nutrition to the poorest of the poor. India is the third-largest poultry industry after China and USA and the fourth-largest chicken producer after China, Brazil and USA. India occupies $3^{\text {rd }}$ place in the world egg production and is among the twenty top producers in the world. Layers in India have registered an annual compounded growth rate of $7 \%$ to $8 \%$ for the past three decades $\left(19^{\text {th }}\right.$ Livestock census 2012). 
The mean poultry waste generated per bird per day was estimated at $0.11 \mathrm{~kg}$ so that millions of metric tons poultry manure is annually generated. Estimates of the manure excreted by 1000 birds per day (based on average daily live weights during the birds' production cycle) are approximately $120 \mathrm{~kg}$ for layer chickens, $80 \mathrm{~kg}$ for meat chickens (Williams, C. M. 2013).

The major occupation of Namakkal people is poultry farming. In Tamil Nadu, Namakkal ranks first in egg production. The daily average egg production in Namakkal Zone has increased to 341.18 lakh eggs a day. Poultry wastes remain high in this area. Therefore, to assess the awareness among the people about the poultry waste management and its disposal through questionnaire survey. Survey was carried out in three villages namely, Mohanur, Valayapatty, Ladduvaddi, Parali in Namakkal.

\section{Materials and Methods}

In all the four selected villages of Namakkal, intensive questionnaires survey has made in 4 villages namely, Mohanur, Valayapatty, Ladduvaddi, Parali to know how the poultry waste disposed and environmental issues related to the poultry waste disposal method. This survey mainly consists of series questions. Questionnaire played major role to survey. Based the questionnaire, survey was conducted. The following questions are interviewed with the farmers for estimating and assessing their awareness about the poultry waste and its management which includes How much birds are in the farm; Where the birds faecal matters disposed; Any health problem due to the waste; Time interval between waste collections; Total area of the farm; Selling price per ton of waste; Are you applying waste for the Agriculture field; Any ill effect to the nearer field; Any waste processing in the farm; Are you aware of water pollution due to poultry waste. Nearly 25 to 30 farmers in each selected villages were responded for the survey. Based on the response the studied was proceeded and their awareness level was assessed.

\section{Results and Discussion}

Based on the questionnaire survey on poultry waste management conducted in 4 villages namely Parali, Valayapatty. Mohanur, Ladduvadi of Namakkal District, Tamil Nadu, the outcome of the study is discussed under various topics.

\section{Major type of poultry sheds in the villages}

Brooder / chick shed in which brood and eggtype chicks from 0 to 8 weeks of age were reared.

Grower Shed where egg-type birds from 9 to 18 weeks of age were grown.

Layer Shed in which birds over 18 weeks of age are reared, usually up to 72 weeks of age were grown.

\section{Size of poultry farm}

In the selected villages, mostly medium and large size farmers are there, holding more than 10000 to 2 lakh birds (Table 1).

\section{Water source}

Mostly bore wells are the source of water for poultry farming. Managing these poultry byproducts as potential pollutants centres on water and air quality concerns, and in some cases on soil quality is highly difficult task for the farmers (Williams, 2013). Only few people avail the well water source. The Kaveri River in Namakkal was also one of the sources of irrigation in these villages. 


\section{Poultry waste disposal}

The poultry droppings disposal method and the usages surveyed among the poultry farming community were discussed below:

\section{Usage of poultry droppings}

In these villages, poultry droppings are used as manure for crops and also used for electricity production. But only very few people are aware of the electricity production through poultry droppings (Fig. 1). Biogas systems are highly friendly to the environment. One of the options to utilize biogas is to produce electricity using a gas engine or gas turbine (Karki et al., 2005). The major farms in this district has stair step multiple cages for layers, chicks, growers.

Mostly layers are grown in Namakkal as the egg production is the highest in this district. The result of the survey is that poultry farmers use only $25 \%$ of poultry wastes as manure. This result shows that farmers use the poultry waste as manure for crops. This poultry manure increases yield in sorghum and fodder crops. Poultry manure has significant, positive yield increases under strip-till or no-till practices; higher yields were observed from cotton, corn, soybean, and peanut crops amended with poultry manure; and yield benefits were more pronounced with repeated applications (Spargo et al., 2011). Poultry waste source of $\mathrm{N}$ gave 17 to $50 \%$ greater cotton seedling counts than ammonium nitrate during the first 4 day of emergence (Nyakatawa et al., 2000). Organic matter in an animal-based rotation which included poultry manure, and another study recently reported that poultry manure application prior to raspberry planting improved soil bulk density and aggregation relative to control and cover crop treatments (Forge et al., 2016).

Only $21 \%$ of the people in these regions are aware of the environmental impact and threat of disease spread from poultry farms. About $80 \%$ of the poultry dropping waste are sent to Kerala at the rate of Rs.1200 per ton for coconut and Arecanut grooves for manure purpose (Fig. 2). Poultry manure application to pasture and cropland has long been documented as a contributing source of nonpoint source (NPS) pollutants N and P to downstream waters through surface (Soupir $e t$ al., 2006). Excessive land application of poultry wastes has precipitated severe water quality problems in surface waters and ground- waters throughout the region. Impacts include harmful algal blooms, decreases in water clarity, widespread anoxia, and declines in submerged aquatic vegetation (Gerber et al., 2007).

Table.1 Size of poultry holding in the selected villages

\begin{tabular}{|l|l|l|c|}
\hline S. No. & Size of the poultry farm & Number of birds & No. of poultry farms \\
\hline $\mathbf{1}$ & Small size farm & less than 10000 & 3 \\
\hline $\mathbf{2}$ & Medium size farm & $10000-50000$ & 6 \\
\hline $\mathbf{3}$ & Large size farm & Above 50000 & 5 \\
\hline
\end{tabular}




\section{POULTRY FARMERS AWARENESS OF USAGE OF POULTRY DROPPINGS}

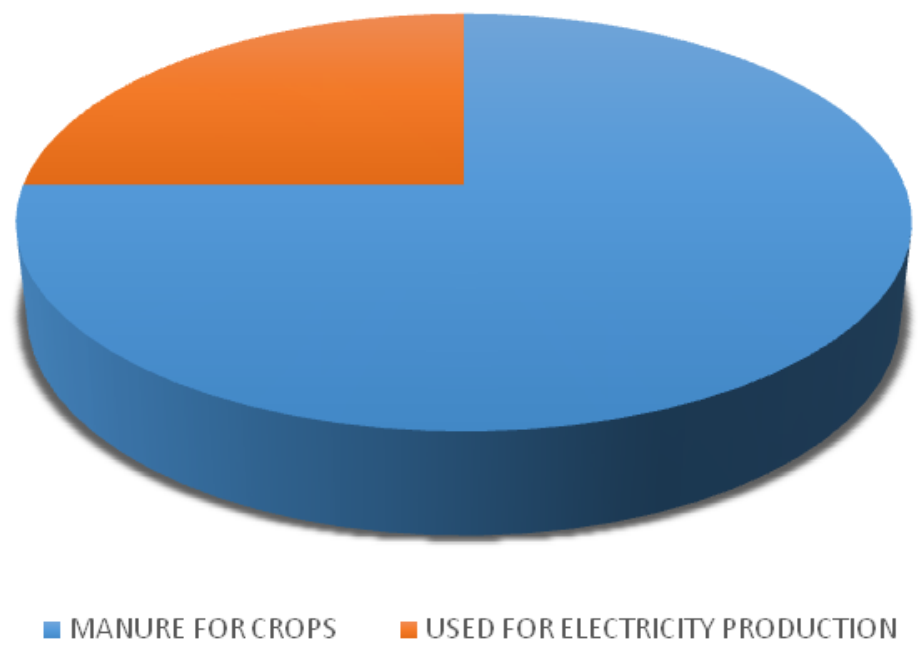

\section{POULTRY DROPPINGS DISPOSAL METHOD IN THE SELECTED VILLAGES}

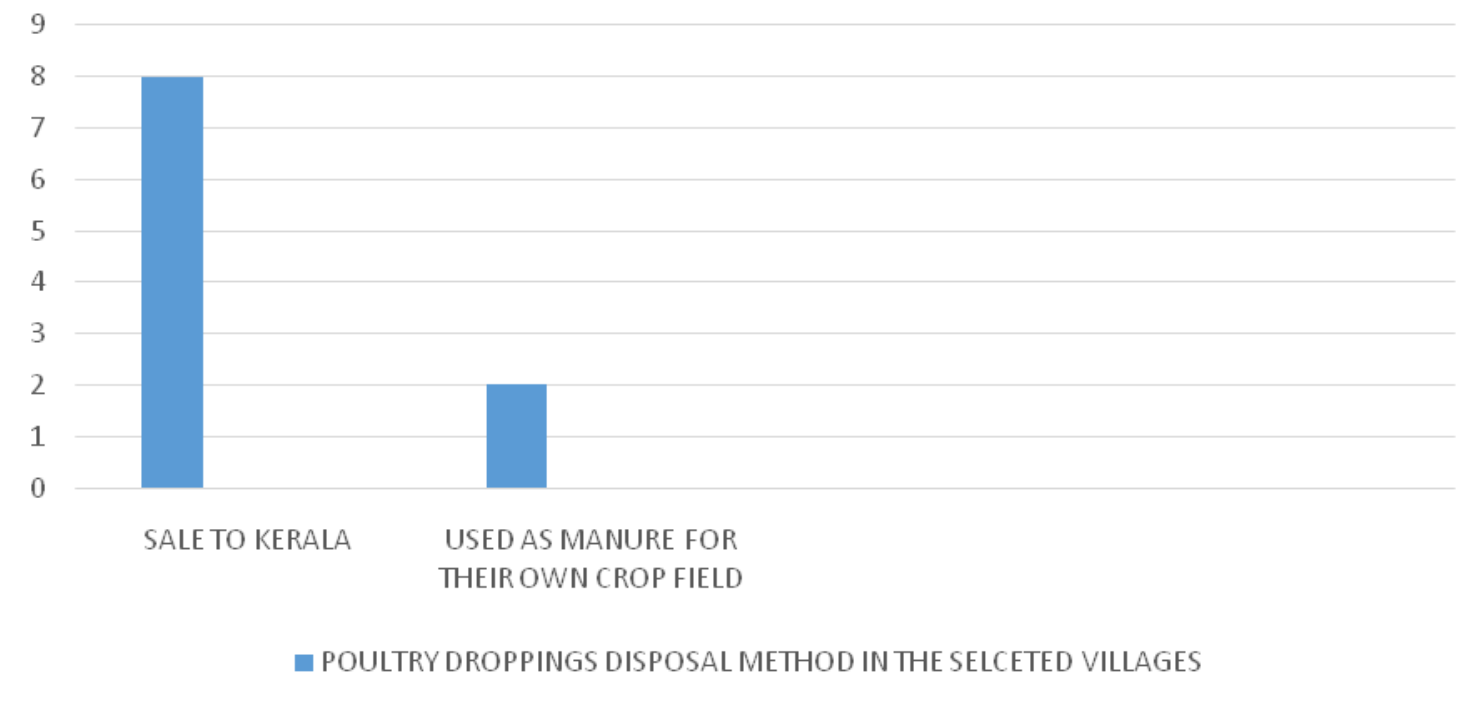

The method of disposal of poultry waste plays a major role in controlling and eradication of infectious diseases. Inadequate approach and carelessness of this essential aspect of production process in poultry, will lead to constant threat of disease ailments on poultry farms (Thyagarajan, 2013). The people of these selected villages are unaware of the pollution and hygienic problems raised because of the improper disposal of these poultry wastes in to the environment

Summary and conclusion are as follows:

Based on the study conducted in the selected villages of Namakkal District, it can be 
concluded that the people of theses villages are aware of utilization of these poultry droppings as manure for crops and for electricity production. Also, though the people are aware of environmental hazard that arises due to improper disposals of these wastes in the agricultural and barren lands, they did not implement proper disposal method. Proper disposal technologies have to disseminate among the farmers and other poultry growers for reduction of environmental impact of these wastes for environmental sustainability.

\section{References}

Forge, T. A., Hannam, K. D., Neilsen, G. H., Neilsen, D., Losso, I., Jones, M. D., and Fentabil, M. M. (2016). Irrigation practices, nutrient applications, and mulches affect soil nutrient dynamics in a young Merlot (Vitis vinifera L.) vineyard. Canadian Journal of Soil Science, 96(1), 23-36.

Gerber, P., Opio, C., and Steinfeld, H. (2007). Poultry production and the environment - a review. Animal production and health division, Food and Agriculture Organization of the United Nations, Viale delle Terme di Caracalla, 153.

Karki, S. K., Mann, M. D., and Salehfar, H. (2005). Energy and environment in the
ASEAN: challenges and opportunities. Energy Policy, 33(4), 499-509.

Nyakatawa, E. Z., Reddy, K. C., and Mays, D. A. (2000). Tillage, cover cropping, and poultry litter effects on cotton: II. Growth and yield parameters. Agronomy Journal, 92(5), 1000-1007.

Soupir, M. L., Mostaghimi, S., and Yagow, E. R. (2006). Nutrient Transport from Livestock Manure Applied to Pastureland Using Phosphorus- Based Management Strategies. Journal of environmental quality, 35(4), 12691278.

Spargo, J. T., Cavigelli, M. A., Mirsky, S. B., Maul, J. E., and Meisinger, J. J. (2011). Mineralizable soil nitrogen and labile soil organic matter in diverse long-term cropping systems. Nutrient Cycling in Agroecosystems, 90(2), 253-266.

Statistics, B. B. A. H. 19th Livestock census (2012). DAHDF, Ministry of Agriculture, 65-73.

Thyagarajan, D., Barathi, M., and Sakthivadivu, R. (2013). Scope of poultry waste utilization. IOSR $J$. Agric. Vet. Sci., 6(5), 29-35.

Williams, C. M. (2013). Poultry waste management in developing countries. The role of poultry in human nutrition, 46.

\section{How to cite this article:}

Sasi, S. P. and Suganya, K. 2020. Assessing the Environmental Awareness among the Farmers of Namakkal District about the Eco-Friendly Poultry Waste Management Techniques. Int.J.Curr.Microbiol.App.Sci. 9(11): 1946-1950. doi: https://doi.org/10.20546/ijcmas.2020.911.230 